\title{
Evaluation of the antibacterial effects of aqueous and ethanolic leaf extracts of Aloysia Citriodora (Lemon verbena) on Streptococcus mutans and Streptococcus sobrinus
}

\author{
Faranak Shafiee ${ }^{1}$, Ali Akbar Moghadamnia ${ }^{2}$, Zahra Shahandeh ${ }^{3}$, Farhnaz Sadighian ${ }^{4}$, Effat Khodadadi ${ }^{5}$
}

${ }^{1}$ Postgraduate Student, Faculty of Dentistry, Babol University of Medical Sciences, Babol, Iran

${ }^{2}$ Department of Pharmacology and Toxicology, Faculty of Medicine, Babol University of Medical Sciences, Babol, Iran

${ }^{3}$ Department of Laboratory Sciences, Paramedical Faculty, Babol University of Medical Sciences, Babol, Iran

${ }^{4}$ Department of Laboratory Sciences, Paramedical Faculty, Babol University of Medical Sciences, Babol, Iran

${ }^{5}$ Dental Materials Research Center, Department of Pediatrics, Faculty of Dentistry, Babol University of Medical

Sciences, Babol, Iran

Type of article: Original

\begin{abstract}
Introduction: The Aloysia citriodora plant from the family of Verbenaceae has many uses in traditional medicine. The aim of the current study was to determine the effects of the aqueous and ethanolic extracts of $A$. citriodora on Streptococcus mutans and Streptococcus sobrinus, which cause tooth decay.

Methods: This 2016 study was performed on standardized strains of S. mutans PTCC1683 and S. sobrinus PTCC1601 and clinical isolates. Twenty clinical samples were obtained from the dental caries of children admitted to the pediatric ward at the Faculty of Dentistry of Babol University of Medical Sciences (Babol, Iran). The aqueous and ethanolic extracts of $A$. citriodora leaves were prepared in several concentrations ranging from $625-20,000 \mu \mathrm{g} / \mathrm{ml}$. These concentrations of the extracts were applied to the bacteria by disk diffusion, agar well diffusion, and macrotube dilution. The antibacterial effects of amoxicillin and chlorhexidine digluconate $0.2 \%$ (CHX) were also carried out. Data were analyzed by SPSS version 18 software using independent-samples t-test. Results: Streptococcus spp. was successfully isolated from nine out of $20(45 \%)$ specimens. Of the 9 positive samples cultured, $8(88.8 \%)$ were S. mutans and 1 was S. sobrinus $(11.2 \%)$. No inhibitory zone was observed around the disks and wells containing all concentrations of $A$. citriodora extracts. The minimum concentrations for inhibition of growth (MIC) resulted in turbidity in all tubes and were negative except for the control tubes. Inhibition zones were observed for amoxicillin and CHX disks $(p<0.001)$.

Conclusion: This study found that all studied bacteria were resistant to both types of the extracts; therefore, they are not a suggested replacement for chemical agents in mouthwash. It also shown that CHX is less effective than amoxicillin.
\end{abstract}

Keywords: A. citriodora, Amoxicillin, Chlorhexidine digluconate (CHX), S. mutans, S. sobrinus

\section{Introduction}

Dental caries is the most common chronic disease worldwide (1). Dental caries is defined as infectious bacterial disease that results in destruction of the calcified tissue of the teeth (1). One of the bacteria attributed to dental caries is Streptococcus mutans, with eight serotypes that are part of the normal flora in oral cavity. The two species responsible for the initiation of dental caries in man are Streptococcus mutans and Streptococcus sobrinus (2). A caries prevention method is a complex process comprised of multiple aspects (1). Its primary aim is to reduce the numbers of cariogenic bacteria. To reach this goal, limiting substrate, disrupting of plaque formation with brushing and flossing, modifying tooth surface with different topical treatment such as CHX or antibiotic treatment can be applied (1). The golden standard for mouth rinses is CHX. Reversible side effects of CHX use are brown staining of

\section{Corresponding author:}

Dr. Effat Khodadadi, Department of Pediatrics, Faculty of Dentistry, Babol University of Medical Sciences, Babol, Iran. Tel: +98.9111116180, Email: Dr_ekhodadadi@yahoo.com

Received: May 09, 2016, Accepted: July 13, 2016, Published: December 2016

iThenticate screening: July 10, 2016, English editing: September 26, 2016, Quality control: October 08, 2016

(C) 2016 The Authors. This is an open access article under the terms of the Creative Commons Attribution-NonCommercialNoDerivs License, which permits use and distribution in any medium, provided the original work is properly cited, the use is non-commercial and no modifications or adaptations are made. 
the teeth, sores, sloughing, and dry mouth. Furthermore, the development of drug resistance in human pathogens against commonly used antibiotics has necessitated a search for a new antimicrobial substance from other sources, including plants (3). The therapeutic benefits of herbal antimicrobial agents as an alternative to chemical antimicrobial agents has been considered in medicine. Their antimicrobial characteristics, which do not affect the normal flora of the oral cavity, make them a suitable replacement for chemical substances. This replacement could result in overcoming the chemical side effects, which is a positive step in improving health and oral hygiene (4). Aloysia citriodora is an herb from the family of Verbenaceae, with many medicinal properties. A. citriodora is listed as a safe substance by the American Food and Drug Administration (FDA), and the consumption of its alcoholic and tea forms have been deemed safe for use (5). The leaves of this plant contain aromatic compounds and are used to make herbal tea. Phenolic compounds are part of the aromatic substances identified in the aqueous and ethanolic extracts of A. citriodora, which include dihydrocaffeic acid, 4-hydroxycinnamic acid, luteolin-7-o-glycoside. These substances are responsible for the antimicrobial, anti-inflammatory, and antioxidant activities $(6,7)$. The objective research was to determine the effects of the aqueous and ethanolic extracts of $A$. citriodora on clinical isolates and standardized strains of S. mutans and S. sobrinus.

\section{Material and Methods}

\subsection{Collection of plant sample and preparation of aqueous and ethanolic extracts of $A$. citriodora}

A. citriodora leaves were collected from the campus at Babol University of Medical Sciences and washed and dried in the shade at room temperature (RT) for 72 hours. Then, they were grinded to make powdered. To prepare the aqueous extract, $48 \mathrm{~g}$ of the powdered herb was mixed with $100 \mathrm{ml}$ boiled water cooled to $70{ }^{\circ} \mathrm{C}-80{ }^{\circ} \mathrm{C}$ and placed at RT for 24 hours. Then, the mixture was passed through filter paper (Whatman filter paper number 1) and left to dry in an oven at $40{ }^{\circ} \mathrm{C}-50{ }^{\circ} \mathrm{C}$. The dried remains were weighted and dissolved in $100 \mathrm{ml}$ sterilized distilled water. This extract was considered an aqueous extract of $A$. citirodora. For the ethanolic extract, $82 \mathrm{~g}$ of powdered plant was soaked in $250 \mathrm{ml}$ of $95 \%$ ethanol in a beaker. The mixture was filtered after 48 hours, as described above. The mixture was then dried by a vacuum device. The weight of the ethanolic extract was measured after drying and diluted in $100 \mathrm{ml}$ sterilized distilled water. The mixture was considered an ethanolic extract of $A$. citriodora. These stock extracts were stored at $4{ }^{\circ} \mathrm{C}$ and used to make several concentrations $(625-20,000 \mu \mathrm{g} / \mathrm{ml})$.

\subsection{Sample collection and tested bacteria}

In this 2016 in vitro study, 20 clinical samples were obtained from the oral caries of children admitted to the children's ward at the Faculty of Dentistry, Babol University of Medical Sciences, after obtaining a signed agreement document from their parents. Exclusion criteria were no history of systemic diseases, no medication, no usage of topical fluoride and anti-septic mouthwash during the past month, and a caries index $\leq 5$. Dental plaque from decayed teeth was taken with a sterile swab and placed in a capped tube containing $5 \mathrm{ml}$ of brain heart infusion broth (BHI) (Himedia) and sent to the microbiology laboratory in a cool box with ice (8). Standardized strains of $S$. mutans PTCC1683 and S. sobrinus PTCC1601 were also obtained. The dental swabs were cultured on Columbia sheep blood agar (SBA); then a streak culture method was used to separate bacterial colonies, incubated for 48 hours at $35^{\circ} \mathrm{C}$ and $5 \% \mathrm{CO} 2(9,10)$. A gram stain was carried out for colonies suspected as Streptococcus spp. Then, the catalase test and hemolysis reaction were assessed. Furthermore, biochemical tests such as bile tolerance, susceptibility to optochin disks, and hydrolysis of Pyrrolidonyl- $\alpha$-naphthylamide (PYR) (Himedia) were preformed (11). In order to differentiate $S$. mutans and S. sobrinus, other biochemical tests such as esculin hydrolysis, production of urease, fermentation of sorbitol, melibiose, salicin, mannitol, and raffinose were carried out (10).

\subsection{Disk diffusion}

Bacterial suspensions with a concentration equal to $0.5 \mathrm{McF}$ arland were made for the standardized strains and the isolated bacteria from the clinical samples. These bacteria were cultured on Muller-Hinton agar (Himedia) containing $5 \%$ sheep's blood using the spread plate method $(8,9)$. Then, sterile paper disks containing concentrations ranging from $625-20,000 \mu \mathrm{g} / \mathrm{ml}$ of the aqueous and ethanolic extracts, $25 \mu \mathrm{g}$ amoxicillin disks (A25C MAST), CHX mouthwash $0.2 \%$ (Mehban) were placed on the medium. Disks were placed $15 \mathrm{~mm}$ from the edge of the plate and $24 \mathrm{~mm}$ from the center of adjacent disks. The plates were incubated at $35^{\circ} \mathrm{C}$ and $5 \% \mathrm{CO} 2$ for 24 hours, and then the diameters of the growth inhibition zone were measured $(8,9)$. Disks containing only sterilized distilled water and ethanol (extract solvent) were used as negative controls $(11,16)$.

\subsection{Agar well diffusion}

Bacterial suspensions were prepared as the disk diffusion method and cultured on BHI agar by the spread plate technique. Then, wells were made on the plates by a sterilized Pasteur pipette and 50-100 $\mu 1$ of varying 
concentrations of extracts and mouthwash were added to the wells. Mouthwash was used as a positive and sterilized distilled water and ethanol (extract solvent) were used as a negative control. The plates were kept in RT for $30 \mathrm{~min}$ and then incubated at $35^{\circ} \mathrm{C}$ for 24 hours. The diameters of the inhibition zones were measured $(13,14)$.

\subsection{Determination of MIC values}

In order to calculate MIC, cation-adjusted Muller-Hinton broth (CAMHB) (Himedia) medium containing lysed horse blood (LHB) was used in accordance with Clinical \& Laboratory Standards Institute (CLSI guidelines) (12). In brief, different concentrations $(1-32 \mu \mathrm{g} / \mathrm{ml})$ of amoxicillin solution were made using phosphate buffer saline (PBS) and then added to tubes containing CAMHB medium (12). Microbial suspensions with a concentration equal to $0.5 \mathrm{McFarland}$ were also added to the tubes resulting in $5 \times 10^{5} \mathrm{cfu} / \mathrm{ml}$ bacteria. The tubes were incubated at $35^{\circ} \mathrm{C}$ for 24 hours, and turbidity was measured by a spectrophotometer at $625 \mathrm{~nm}$ (9). To confirm MIC results, a loop of each tube was cultured on Columbia blood agar medium at $35^{\circ} \mathrm{C}$ in the presence of $5 \% \mathrm{CO} 2$ for 48 hours for colony counting. Each experiment had a positive (medium with bacteria) and negative controls (medium without bacteria). The same experiments as described above were carried out for different concentrations $(625-20,000 \mu \mathrm{g} / \mathrm{ml})$ of the $A$. citriodora extracts.

\subsection{Statistical analysis and ethical consideration}

The data were processed by SPSS version 18.0 and an independent-samples t-test was used to compare the results of disks of amoxicillin and CHX groups, and a $p<0.05$ was considered significant. This study was certified by the Ethics Committee (grant number 9441012) of the Research Council of Babol University of Medical Sciences, Babol, Iran.

\section{Results}

Twenty children, aged 6-12 years old, including nine girls and 11 boys, participated in this study. The mean of caries indices were DMFT $=3.8$ and $\mathrm{dmft}=5.3$. Streptococcus spp. was successfully isolated from nine out of 20 (45\%) specimens. Of the 9 positive samples cultured, 8 (88.8\%) were $S$. mutans and 1 (11.2\%) was $S$. sobrinus. All bacteria grew in the presence of all concentrations of the aqueous and ethanolic leaf extracts of $A$. citrodora (625$20,000 \mu \mathrm{g} / \mathrm{ml}$ ), and no inhibition zones were observed around the disks and wells using the disk diffusion and agar well diffusion methods. This study demonstrated that all the studied bacteria with inhibition zones of more than 30 $\mathrm{mm}$ and $12 \mathrm{~mm}$ grew around the amoxicillin and CHX disks $(p<0.001)$ and wells, respectively, using the aforementioned methods (Tables 1,2). In the third test, which was used to determine MIC, turbidity was seen in all the tubes excluding the negative control tubes. This shows the significant growth of bacteria and the ineffectiveness of the extracts. The MIC results for amoxicillin is shown in Table 3.

Table 1. Mean of inhibition zones diameters (mm) of amoxicillin, CHX, aqueous and ethanolic extracts of $A$. citriodora determined using disk diffusion method

\begin{tabular}{|c|c|c|c|c|c|}
\hline \multirow{2}{*}{\multicolumn{2}{|c|}{ Bacteria }} & \multirow{2}{*}{\multicolumn{4}{|c|}{ Antibacterial agents }} \\
\hline & & & & & \\
\hline \multirow{2}{*}{$\begin{array}{l}\text { Standardized } \\
\text { strains }\end{array}$} & S. mutans $(n=1)$ & 46 & 20 & 0 & 0 \\
\hline & S. $\operatorname{sobrinus}(n=1)$ & 48 & 16 & 0 & 0 \\
\hline \multirow[t]{2}{*}{ Clinical isolates } & S.mutans $(n=8)$ & $38.25 \pm 3.8^{*}$ & $16.00 \pm 1.77 *$ & 0 & 0 \\
\hline & S. sobrinus $(n=1)$ & 32 & 12 & 0 & 0 \\
\hline
\end{tabular}

0 means no growth inhibition zones, * Mean \pm SD $(\mathrm{p}<0.001)$, Amioxicillin $25 \mu \mathrm{g} /$ disk

Table 2. Mean of inhibition zones diameters $(\mathrm{mm})$ of $\mathrm{CHX}$, aqueous and ethanolic extracts of $A$. citriodora determined by well diffusion method.

\begin{tabular}{|l|l|l|l|l|}
\hline \multicolumn{2}{|l|}{ Bacteria } & \multicolumn{4}{|l|}{ Antibacterial agents } \\
\cline { 3 - 5 } \multicolumn{2}{l|}{} & CHX & Aqueous extract & Ethanolic extract \\
\hline \multirow{2}{*}{ Standardized strains } & S. mutans $(n=1)$ & 25 & 0 & 0 \\
\cline { 2 - 5 } & S. sobrinus $(n=1)$ & 22 & 0 & 0 \\
\hline \multirow{2}{*}{ Clinical isolates } & S. mutans $(n=8)$ & $20.25 \pm 2.49^{*}$ & 0 & 0 \\
\cline { 2 - 5 } & S. sobrinus $(n=1)$ & 15 & 0 & 0 \\
\hline
\end{tabular}

0 means no growth inhibition zones, ${ }^{*}$ Mean \pm SD 
Table 3. MIC values of amoxicillin, aqueous and ethanolic extracts of $A$. citriodora

\begin{tabular}{|c|c|c|c|c|}
\hline \multirow{2}{*}{\multicolumn{2}{|c|}{ Bacteria }} & \multicolumn{3}{|c|}{ Antibacterial agents } \\
\hline & & Amoxicillin & Aqueous extract & Ethanolic extract \\
\hline \multirow[t]{2}{*}{ Standardized strains } & S. mutans $(n=1)$ & 16 & 0 & 0 \\
\hline & S. sobrinus $(n=1)$ & 14 & 0 & 0 \\
\hline \multirow[t]{2}{*}{ Clinical isolates } & S. mutans $(n=8)$ & $12.13 \pm 1.52^{*}$ & 0 & 0 \\
\hline & S. sobrinus $(n=1)$ & 32 & 0 & 0 \\
\hline
\end{tabular}

0 means no growth inhibition zones, Amoxicilline concentrations $1-32 \mu \mathrm{g} / \mathrm{ml}$, aqueous and ethanolic extracts concentration $625-20,000 \mu \mathrm{g} / \mathrm{ml}, *$ Mean $\pm \mathrm{SD}$

\section{Discussion}

A. citrodora leaves have many medicinal properties, which may make their extract a suitable replacement for chemical substances in mouthwash. However, no studies have been performed on their effects on tooth decay causing bacteria until now. The results obtained from our study showed that both $S$. mutans and $S$. sobrinus were resistant to the aqueous and ethanolic extracts of $A$. citriodora, as no inhibition of growth of the studied bacteria was observed. A 2010 study by Ramzi showed that Staphylococcus aureus, Bacillus subtilis, and Micrococcus flavus were susceptible to $4000 \mu \mathrm{g} / \mathrm{ml}$ of methanolic extract of A. citriodora while Escherichia coli, Pseudomonas aeruginosa, and the fungal specie of Candida maltosa were resistant (16). A 2005 study by Oskay determined the antimicrobial effects of ethanolic extracts of A. citriodora in concentrations ranging from $4000-20,000 \mu \mathrm{g} / \mathrm{ml}$ on nine species of pathogenic bacteria and four species of fungi. The authors found that the most inhibition of growth was observed for $S$. aureus at $4000 \mu \mathrm{g} / \mathrm{ml}$. Bacillus cereus and Micrococcus luteus had low susceptibility. Pseudomonas fluorescens and Saccharomyces cerevisiae were completely resistant (23). However, one possible explanation for our results is the production of biofilm by S. mutans, as it is a planktonic bacteria that can produce intra and extracellular polysaccharides by producing the glycosyl-transferase enzyme $(27,28)$. This is an important factor in the formation and cohesion of biofilm. Bacteria, which produce biofilm, are generally more resistant to antimicrobial agents $(24,25)$. Another reason may be due to the chemical compounds in the extract. Studies have reported that extracts are rich in polyphenols, which have anti-Streptococcus spp. activities via the inhibition of cell adhesion and formation of biofilm and the reduction of cell surface hydrophobicity. Literature has stated that antibacterial activity may be related to the number of oligomeric epicatechin units and interflavonoid bonds in $A$. citrodora extract, while monophenolic structures and compounds such as phenolic acid do not affect the bacteria (25). It should be mentioned that the chemical components of a plant extract may be different from region to region based on climatic conditions and different varieties of the plant (26).

\section{Conclusions}

The current study demonstrated that aqueous and ethanolic extracts of A. citriodora have no bactericidal or bacteriostatic effects on $S$. mutans and $S$. sobrinus. Because the aim of this study was not to fractionize the components present in the extract and assess their roles, we cannot give a definite opinion based on the results. Taking into account the medicinal uses in other circumstances, future studies, particularly on the essence, may clarify the possible mechanism involved.

\section{Acknowledgments:}

The authors appreciate the financial support of the Research Center of Babol University of Medical Sciences (grant number 9441012). We also thank Ms. Mahdis Alaodolehee for aiding in experimental procedures.

\section{Conflict of Interest:}

There is no conflict of interest to be declared.

\section{Authors' contributions:}

All authors contributed to this project and article equally. All authors read and approved the final manuscript.

\section{References:}

1) Pikham JR, Casamassimo PS, Fields HW, Mctigue DJ, Nowak AJ. 4th ed. St. Louis, Missouri: Elsevier Inc; 2013. Pediatric Dentistry Infancy Through Adolescence. 199-204. 286.

2) Mcdonald RE, Avery DR, Dean JA. 8th ed. St. Louis, Missouri: Mosby, Inc; 2011. Dentistry for the Child and Adolescent. 205-14. 
3) Carranza FA, Newman MG, Takei D. Clinical periodontology. 10thEd. Philadelphia, WB Saunders. 2006; 9: 134-42.

4) Vahabi S, Najafi E, Alizadeh S. In vitro antimicrobial effects of some herbal essences against oral pathogens. J Med Plan Res. 2011; 5(19): 4870-8.

5) Chavallier A. The Encyclopedia of Medicinal Plants: A Practical Reference Guide to over 550 Key Herbs and Their Medicinal Uses. London: Dorling-Kinderseley. 1996; 227.

6) Ombito JO, Salano EN, Yegon PK, Ngetich WK, Mwangi EM. A rewiew on the chemistry of some species of genus Lippia (Verbenaceae family). J Sci Res. 2014; 3(4): 460-6.

7) Seham SE, Miriam FY, Motaal AA, Hameed LMA. Bioactivities, phenolic compounds and in vitro propagation of Lippia citriodora Kunth cultivated in Egypt. Bull faculty Pharm. 2012; 50(1): 1-6. doi: 10.1016/j.bfopcu.2011.12.001.

8) Gamal M, EI-Sherbiny. Control of group Streptococcus mutans isolated from saliva and dental caries. Int J Cur Mic App Sci. 2014; 3(10): 1-10.

9) Geetha RV, Roy A. In vitro evaluation of antibacterial activity of ethanolic root extract of Glycyrrhiza on oral microbes. Int J Drug Dev Res. 2012; 4(4): 161-5.

10) Washington C, Winner JR, Stephen DA, William MJ, Elmer WK, Gary WP. Konemen's color atlas and textbook of diagnostic microbiology. 6th edition. 2006; 722-4.

11) Akinjogunla OJ, Adenugba IT, Jumbo Om. Invitro antibacterial evaluation of ethanolic stem crude extracts of Anacardium occidental Linn. (Anacardiaceae) on Streptococcus mutans associated with dental caries. Sci J Mic. 2012; 1: 71-81.

12) Methods for Dilution Antimicrobial Susceptibility Tests for bacteria that grow aerobically, Approved standard-Tenth Edition. 2012; 35(2).

13) Helmy MM, Bakr RO. In vitro comparison of antimicrobial activity of five herbal extracts, and selected mouthwashes marketed in Egypt against cariogenic Streptococcus mutans. Egypt J Med Mic. 2014; 23(1): 49-58. doi: 10.12816/0024259.

14) Aldhaher ZA. Antimicrobial activity of different types of mouthwashes against Streptococcus mutans, Staphylococcus aureus and Candida albicans (In vitro study). Bagh Coll Den. 2013; 25(2): 185-91. doi: $10.0001 / 249$.

15) Performance standards for Antimicrobial Susceptibility Testing; 24th edition, informational supplement. 2014; 34(1): 100-24.

16) Mothana RA, Abdo SA, Hasson S, Althawab FM, Alaghbari SA, Lindequist U. Antimicrobial, antioxidant and cytotoxic activities and phytochemical screening of some Yemeni medicinal plants. Evid Based Complement Alternat Med. 2010; 7(3): 323-30. doi: 10.1093/ecam/nen004. PMID: 18955315, PMCID: PMC2887327.

17) Santos-Gomesa PC, Fernandes-Ferreiraa M, Vicente AMS. Composition of the essential oils from flowers and leaves of vervain. J Essent Oil Res. 2005; 17(1): 73-8. doi: 10.1080/10412905.2005.9698835.

18) Alavi L, Barzegar M, Jabbari A, Naghdi badi H. The effect of heat treatment on chemical composition and antioxidant property of Lippia citriodora Essential oil. J Med Pla. 2011; 10(39): 65-75.

19) Quirantes-Piné R, Herranz-López M, Funes L, Borrás-Linares I, Micol V, Segura-Carretero A, et al. Phenylpropanoid and their metabolites are the major compounds responsible for blood cell protection against oxidative stress after administration of Lippia citriodora in rats. Phytomedicine. 2013; 20(12): 1112-8. doi: 10.1016/j.phymed.2013.05.007. PMID: 23827667.

20) Portman E, Nigro MM, Reides CG, Liesuy S, Ricco RA, Wagner ML, et al. Aqueous extracts of Lippia turbinate and Aloysia citriodora (verbenaceae): assessment of antioxidant capacity and DNA damage. Int J Toxicol. 2012; 2: 192-202. doi: 10.1177/1091581812436726. PMID: 22427199.

21) Ohno T, Kita M, Yamaoka Y, Imamura S, Yamamoto T, Mitsufuji S, et al. Antimicrobial activity of essential oils against Helicobacter pylori. Helicobacter. 2003; 8(3): 207-15. doi: 10.1046/j.15235378.2003.00146.x. PMID: 12752733.

22) Valentão P, Fernandes E, Carvalho F, Andrade PB, Seabra RM, de Lourdes Basto M. Studies on the antioxidant activity of Lippia citriodora infusion:scavenging effects on superoxide radical, hydroxyl radical and hypochlorus acid. Biol Pharm Bull. 2002; 25(10): 1324-7. doi: 10.1248/bpb.25.1324. PMID: 12392088

23) Oskay M, Usame Tamer A, AY G, Sari D, Aktas K. Antimicrobial activity of the Leaves of Lippia triphylla O. Kuntze (Verbenaceae) against on bacteria and yeasts. J Biol Sci. 2005; 5(5): 620-2. doi: $10.3923 /$ jbs.2005.620.622. 
24) Duarte S, Gregoire S, Singh AP, Vorsa N, Schaich K, Bowen WH, et al. Inhibitory effects of cranberry polyphenols on formation and acidogenicity of Streptococcus mutans biofilms. FEMS Mic Lett. 2006; 257(1): 50-6. doi: 10.1111/j.1574-6968.2006.00147.x. PMID: 16553831.

25) Abachi S, Lee S, Rupasinghe HP. Molecular mechanisms of inhibition of Streptococcus species by phytochimecal. Molecules. 2016; 21(2): 215. doi: 10.3390/molecules21020215. PMID: 26901172.

26) Paun G, Zrira S, Boutakiout A, Ungureanu O, Simion D, Chelaru C, et al. Chemical composition, antioxidant and antibacterial activity of essential oils from Moroccan aromatic herbs. Riv Rum Chim. 2013; 58(11-12): 891-7.

27) Carvalho Galvao LC, Furlitti VF, Fernandes Bersan SM, Da cunha MG, Tasca Guis Ruis AL, De carvalho JE, et al. Antimicrobial activity of essential oils Streptococcus Mutans and their antiproliferative effects. Evid base Com Alt Med. 2012. doi: 10.1155/2012/751435.

28) Golestannejad Z, Mohammadi E, Motamedi A, Gavanji S, Fallah N, Bagheri S, et al. Chemical composition and antibacterial activity of some herbal essential oils against Streptococcus mutans. Advan Herb Med. 2015; 1(3): 1-8. 